\title{
Photographs of the nebula in orion
}

\section{Prof. Henry Draper M.D.}

To cite this article: Prof. Henry Draper M.D. (1880) Photographs of the nebula in orion, Philosophical Magazine Series 5, 10:63, 388-388, DOI: 10.1080/14786448008626947

To link to this article: http://dx.doi.org/10.1080/14786448008626947

$$
\text { 曲 Published online: } 08 \text { May } 2009 .
$$

6 Submit your article to this journal $\pi$

LII Article views: 2

Q View related articles $\asymp$ 
(especially at a small negative one) immersed in liquids when the current is of considerable intensity.

According to Colley, in a rotating mirror a series of bright stars irregularly distributed upon a feebly illuminated ground are at the same time perceived; so that consequently the individual discharges issue from different parts of the electrode, while the time of the passage of the current is very short in comparison with that of the intermissions.

The spectrum at a negative electrode of platinum in dilute sulphuric acid shows, when 96 Bunsen elements are employed, at first the red (bright) and blue hydrogen-lines. In solutions of chloride of sodium and chloride of lithium the lines of those metals are seen in addition, and also (particularly five) platinum-lines are well seen.

Only by chance is the electrode herewith so strongly heated that the liquid no longer wets it. The passage of the spark cannot be owing to this, since the electrode may be quite cold and yet luminous. In order to prove this, Colley fixes in the neck of an inverted flask without a bottom a glass tube, in the upper end of which a platinum tube is cemented, and conducts a stream of cold water through. The flask is filled up to about 1 millim. above the upper extremity of the glass tube with dilute sulphuric acid, into which a cylinder of platinum foil dips. If the platinum tube, only a small surface of which is in contact with the sulphuric acid, serves as the negative, the foil as the positive electrode, yet the light appears. From this it follows that the high temperature really falls upon the liquid surrounding the electrode, which, on account of its small surface, opposes a great resistance to the current. As can easily be calculated, a current from 100 Bunsen cells could in fact readily heat to ebullition dilute sulphuric acid $\left(\frac{1}{5}\right)$ close to an electrode of 10 square millims. surface, whereupon the passage of the sparks then ensues in the vapour, while the rest of the liquid and the electrode are only secondarily heated. Even when, in a narrow aperture, sparks are formed in the liquid itself, as Righi has observed, this arises from the formation of vapour there in consequence of the great resistance and the corresponding heating of the liquid.Wiedemann's Beiblïtter, 1880, No. 9, pp. 684, 685.

\section{PHOTOGRAPHS OF THE NEBULA IN ORION.}

BY PROF. HENRY DRAPER, M.D.

During the night of September 30,1880, I succeeded in photographing the bright part of the nebula in Orion in the vicinity of the trapezium. The photographs show the mottled appearance of this region distinctly. They were taken by the aid of a triple objective of 11 inches aperture, made by Alvan Clark and Sons, and corrected especially for the photographic rays. The equatorial stand and driving-clock I constructed myself. The exposure was for fifty minutes. I intend at an early date to publish a detailed description of the negatives. - Silliman's American Journal, November 1880 .

New York, October 2, 1880. 